\title{
The Prevalence of Tic Disorder in Primary School Children in an Electoral District of Mauritius
}

\author{
Vinu Sharma Chummun ${ }^{1}$, Vanisha Seetaram ${ }^{2}$ and Hugh Rickards ${ }^{3}$ \\ 1. Department of Mental Health, Springwell Centre, Barnet, Enfield and Haringey Trust, London EN5 3DJ, UK \\ 2. Addiction Unit, Ministry Of Health, Port Louis, Mauritius \\ 3. Institute of Clinical Sciences, University of Birmingham, Birmingham B15 2TT, UK
}

\begin{abstract}
Most tic disorder studies have been conducted in countries in the northern hemisphere. So far, there are only 3 studies that have been done in the southern hemisphere countries and they were directed at Tourette syndrome explicitly. This study is the first to examine the prevalence of all tic disorders in the southern hemisphere. Screening questionnaires were sent to all the children in standard 4 to 6 (9-11 years of age - a total of 2003) in the 8 schools of a discrete geographical area. The "tic positive" patients were interviewed and diagnoses were ascertained in accordance with the DSM-IV-TR criteria. Out of the 1287 children screened, 53 (35 males, 18 females) were diagnosed with a tic disorder yielding a prevalence of $4.1 \% .8$ children ( 7 males and 1 female) fulfilled the criteria for Tourette Disorder (0.6\%). Another $0.8 \%$ had chronic tic disorder (6 boys and 4 girls). The majority of people with tics had transient tic disorder at $2.5 \%$ with a male to female ratio of 19 to 13 , respectively. The distribution of non-specific tic disorder was $0.2 \%$ ( 3 males). Tic disorder estimates were congruent with studies performed in the northern hemisphere.
\end{abstract}

Key words: Tic, tourette, prevalence, epidemiology, children.

\section{Introduction}

Tics are sudden, involuntary, rapid, recurrent, non-rhythmic, non-purposeful motor movements or vocalisations [1].

Tourette syndrome is a developmental, neuropsychiatric disorder which typically starts in childhood [2]. It is characterised by a year's duration of multiple motor and at least one vocal tic that are not caused by substances or underlying medical conditions $[1,3]$. The onset of tics is usually between 5 and 7 years of age [4]. The severity of the disorder is exacerbated by the presence of co-morbid conditions [5] which consist primarily of attention-deficit hyperactivity disorder [6-8] and obsessive-compulsive disorder [6, 9]. Patients with Tourette syndrome and Chronic tic disorders can experience disability which can be enduring and impact on their quality of life $[10,11]$. It is more common in males and has been reported in all

Corresponding author: Vinu Sharma Chummun, MBBS, MSc, research field: clinical neuropsychiatry. socio-economic classes and ethnicities [2, 12], but less common in Black Africans [13, 14].

There are only few epidemiological studies on tic disorders that have been carried out in the developing countries. Data on ethnic distribution within these studies are limited. Tourette syndrome was previously believed to be a rare disorder with a rate ranging between $0.02 \%-0.1 \%$ [9, 15, 16]. Recent European studies revealed a higher prevalence rate ranging from $0.5 \%-5.2 \%$ in European studies [17-20]. In Asia, Nomoto and Machiyama [21] carried out a 2 stage study on 1218 children in Japan and they obtained a prevalence rate for all tic disorders of $8.3 \%$ and a prevalence rate for Tourette syndrome of $0.5 \%$. Two prevalence studies in China yielded a rate of $0.4 \%$ [22, 23]. Using the Tourette Syndrome Classification Study Group criteria, Wang and Kuo [24] declared a prevalence rate of Tourette Syndrome (TS) of $0.56 \%$ (11) and Transient Tic Disorder (TTD) of $4.9 \%$ (98) in 2000 Taiwanese children aged 6-12 through screening with a 4 item questionnaire followed by a structured 
clinical interview. The range in Asia was $0.4 \%$ to $0.56 \%$. There are no prevalence studies on Tourette disorder that have been carried out in a predominantly Indian population.

Mauritius is a small south hemispheric country of an area of $2040 \mathrm{~km}^{2}$ and is part of the African Continent. It has a population of 1.2 million, $70 \%$ of whom originate from India and $20 \%$ from Africa. It is a democratic country with 21 electoral constituencies. English is generally accepted as the official language of Mauritius. The majority of the population speaks Creole, a dialect derived mainly from French, which is considered the country's native language.

\section{Methods}

\subsection{Study Design}

This research is an epidemiological survey of tic disorders in an electoral district of Mauritius with clear geographical boundaries. Out of the 20 constituencies in Mauritius, ten of them are urban ones with suburban areas. The electoral quarter of Beau Bassin-Petite Riviere (ward number 20) was randomly chosen out of the above ten by a "drawing of lots" method. It has a total of 8 government mainstream schools with a good mixture of urban and suburban schools. The study consisted of 2 stages. A screening questionnaire was used to screen the target population in the first step. The second stage involved a clinical interview to confirm the diagnosis in line with the DSM-IV-TR criteria [3].

\subsection{Study Population}

Children in Mauritius enter the first standard in mainstream primary schools at an age of between 5 to 6 years. Intake is based on geographical catchment areas. They remain in Primary school until they finish the sixth standard aged 11 years. Thereafter they join secondary schools which are based on academic achievement for seven more years, until the age of 18 years. There is a different stream for the education of children with learning disability and these schools were not included in the study.
All the eight primary schools in the electoral district of Beau Bassin-Petite Riviere were screened in July 2012. The target population comprised children of standards 4 to 6 (age 9 to 11 years) consisting of 1014 boys $(0.51 \%)$ and $989(0.49 \%)$ girls.

This study was reviewed and approved by the Ministry of Education, Government of Mauritius.

\section{Procedure}

The screening questionnaires consisted of an original as well as a translated version (in Creole) of the three-item validated questionnaire developed by Apter et al. [25], both of which were handed to the children. The questionnaires were directed at both parents and children. The parents were requested to fill the questionnaire and return it in the provided envelope through the children. The head teacher was briefed about the research. The first stage included the distribution and collection of questionnaires by teachers. The "tic positive" group consisted of those children whose parents responded positively to at least one of the three questions in the screening form and provided written consent to participation. The researchers made telephone calls to the parents belonging to this group and an appointment was arranged at their convenience.

The second stage consisted of a full clinical interview with the parents and the children. Informed consent was taken from parents and an assent was sought from the children at interview, both of which were necessary for the examination to proceed.

The children were also screened for other psychiatric conditions during the consultation. Clinical observations for any abnormalities were also noted. Diagnosis was confirmed using the DSM-IV-TR criteria [3]. If a chronic tic disorder or Tourette syndrome was confirmed, the parents were asked to fill a Strength and Difficulty Questionnaire to evaluate the presence of co-morbid conditions such as hyperactivity or emotional disorders [26]. The tic symptoms list was extracted from the Yale Global Tic Severity Scale (YGTSS) developed by Leckman [27]. 
Table 1 The lifetime prevalence of tic disorders in the tic positive group.

\begin{tabular}{ccccccccc}
\hline \multirow{2}{*}{ Diagnosis } & \multicolumn{3}{c}{ Age 8-9 } & \multicolumn{2}{c}{ Age 9-10 } & \multicolumn{2}{c}{ Age 10-11 } & \multicolumn{2}{c}{ Total } \\
\cline { 2 - 8 } & M & F & M & F & M & F & M & 7 \\
TD & 1 & - & 3 & 1 & 3 & - & 6 & 1 \\
CTD & 1 & 1 & 1 & 1 & 4 & 2 & 4 \\
TTD & 5 & 3 & 9 & 5 & 5 & 5 & 19 & 13 \\
NSTD & 1 & - & 1 & - & 1 & - & 3 & - \\
\hline
\end{tabular}

TD—Tourette Disorder, CTD — Chronic Tic Disorder, TTD—Transient Tic Disorder, NSTD—Non Specific Tic Disorder.

\section{Results}

Out of the 2003 questionnaires submitted, 1287 (64.2\%) parents responded. A total of 149 participants answered positively to one of the three screening questions. 67 participants were not available for various reasons which included wrong telephone numbers, non response after 3 telephone call attempts, being away on holiday, and withdrawing consent (only 1). Out of the 82 tic positive patients, as illustrated in Table 1, 53 had evidence of tic disorder which translated into a minimum lifetime prevalence rate of $4.1 \%$ (53/1287). Transient tic disorder was the commonest condition with a rate of $2.5 \%$ (32/1287). 8 patients ( 7 males and 1 female) met the criteria for Tourette disorder according to the DSM-IV-TR criteria producing a rate of $0.6 \%$. They all remained symptomatic on interview. Only one patient was already diagnosed with TS.

10 children (6 boys and 4 girls) presented with chronic tic disorder, yielding a lifetime prevalence of $0.8 \% .8$ of them had chronic motor tic disorder and the remaining two had chronic vocal tic disorder. One of the children with chronic motor disorder did not have any current symptoms yielding a point prevalence of $0.7 \%$.

12 of the 32 patients with TTD were still symptomatic on review but their symptoms were present for less than a year. One of the patients in the NSTD group had a history of tics which did not last more than 4 weeks. Two of them were symptomatic on review but the tics did not last for more than 4 weeks.

\section{Discussion}

This is one the first studies to estimate the prevalence rate of tic disorder and its subtypes in a southern hemisphere country using the DSM-IV-TR [3] in this region of the world.

The electoral district of Beau Bassin-Petite Riviere constitutes both urban and suburban areas with a reasonable ethnic balance. The conclusion of a very recent literature review on tic prevalence studies done by Knight et al. [28] recommended complete district based studies rather than isolated school-based ones. All the 8 schools in the district were recruited for the study giving an equal chance of contribution from each of them. Furthermore, all the classes in the school between grades 4 and 6 (age 9-11) were included minimizing any selection bias. It is reported that mean age of onset for Tourette syndrome is 7 years and the majority of children have onset of tics before 11 years $[12,29]$. Consequently, the population of the study was appropriate, well defined, geographically circumscribed with varied ethnicity and reflected generalisability.

The global tic rate of $4.1 \%$ (53/1287) in our study was relatively low compared to other studies but was notably within the reported worldwide range of $1 \%$ to $29 \%$ [30].

\section{Limitations}

The main limitation in the study design was that $34.9 \%$ of the parents, failed to return their questionnaires. A second and third round as initially 
planned could not be carried out to maximize case recruitment. High response rates were obtained in the studies in UK where Hornsey et al. [31] revealed a rate of $90.7 \%$ (918 out of 1012 children) and Mason et al. [17] figured $99 \%$ (166/167). 1579 forms were returned out of 1785 forms distributed in the study performed by Stefanoff et al. [19] in Poland, translating into a rate of $88.5 \%$. Khalifa and von Knorring [18] got a return rate of $44.8 \%$ in their first round, $14.3 \%$ in the second round and $6.6 \%$ in the third round. Most of the diagnoses came out of the first and second round and the rates were almost similar. The third stage found only one diagnostically relevant case. Our study obtained a return rate of $64.2 \%$ (1287/2003) which is reasonable in the light that only a single round of distribution and collection of questionnaires was carried out. Besides, no presentations were carried out in the schools prior to the study as implemented in the study in Poland [19]. Correspondingly, in Sweden, Khalifa and von Knorring [18] had a response rate of $65.7 \%$ (2944/4479).

It could be argued that children who live in the electoral district could attend schools which are out of the borough and the converse might be true as well. However, it is very unlikely that children in this constituency would attend schools that are outside of it, as allocation in government schools is strictly based on catchment area. Out of 1287 returned questionnaires, 18 (1.4\%) lived out of the district and none of them were positive for tics.

One of the other limitations of this study is that a validation study using a reference group was not carried out to test the Creole version of the Apter questionnaire. Nonetheless the sensitivity of this instrument has been proven in other translated versions in various previous studies $[17,19,23,31]$. There is no exact term for tic in the Mauritian dialect Creole but the near equivalent word "Mani" was used. "Mani" means "repeated habits which would include movements or rituals as well". Out of a potential 1287 patients who returned their forms, only 161 (149 completed and 12 incomplete) answered positively to at least one of the four questions which yielded a gross rate of $12.5 \%$ for the "tic questionnaire positive group". This was lower than gross rates of $21 \%$ (189/918) obtained by Hornsey's study and $38.7 \%$ in Stefanoff's study [19]. It is unclear whether the latter's result could be due to an existing equivalent term in Polish. However, Stefanoff and associates did invite parents for a briefing about tics prior to the screening process. The word "mani" on the contrary has a broader meaning "repeated habits". This could in fact maximise recruitment, but the potential of it being misleading cannot also be entirely ruled out especially in the light of a low turnout. However, the result does tally with Mason's study [17] where the latter revealed a gross rate of $14 \%(24 / 167)$ after using the same questionnaire.

The questionnaires in our study were directed at parents but a separate questionnaire to teachers would have been ideal. According to Khalifa's pilot study [18], parents (87.5\%) were more likely to report tics as compared to teachers $(31.1 \%)$. The teachers identified a possible of $46(5 \%)$ relative to the $126(13.7 \%)$ identified by the parents in the 918 pupils in Hornsey's study [31]. There was not much difference between parents $(38.3 \%)$ and teachers $(41.1 \%)$ in Stefanoff's study [19] in spite of the latter carrying out intensive educative sessions about symptoms of tic disorders to the teachers and some parents. It has also been documented that parents tend to overdiagnose and teachers underdiagnose tics [32]. It would have increased the chances of recruiting more children though not considerably but conversely the study would have been considerably protracted and would have been much more expensive because prior parents' approval would have been necessary.

Inclusion and exclusion of impairment has been a source of heterogeneity in studies on prevalence of Tourette disorder producing consequential variations in estimates. Using the DSM-IV rather than the DSM-IV-TR would have possibly decreased the prevalence rate by including the impairment criteria. 
However, if the impairment criterion was removed, 7 of the 8 patients in our study would still have qualified for a diagnosis of Tourette disorder. Most of the parents (except for one) conveyed to the author that the tics had had an impact on their children's performance and general well-being. Assessing and appraising this impact objectively using formal quality of life assessments or carer burden was beyond the scope of the research. Furthermore, the DSM-V plans to retain the non-inclusion of the impairment criteria for diagnosis of tic disorders which makes the diagnostic criteria of the study even more relevant [33]. This would ensure homogeneity in prevalence studies to be carried out in the future assuming that the DSM-V will be used.

We were also unable to ask for ethnicity in the screening questionnaires due to ethical reasons and therefore could not compare the results of the study to the participants.

\section{Conclusion}

This study aimed at estimating prevalence of overall tic disorder and its subtypes in Mauritius, a country with a predominant Indian origin population, is a pioneer in the southern hemisphere. It was a true population based epidemiological study, which enveloped several schools in a well-defined geographical district that was representative of different ethnicities. An overall tic disorder prevalence of $4.1 \%$ was slightly lower than figures obtained globally. On the other hand, a prevalence rate of $0.6 \%$ for Tourette disorder is comparable to studies with similar methodology done in other countries, taking into account that it is the minimum prevalence estimate.

Further population-based prevalence studies on Tourette syndrome are required in the Southern hemispheric countries, and also in India and Africa, to confirm these findings and to evaluate if ethnic differences are present.

\section{Acknowledgement}

The authors thank the Ministry of Education of Mauritius for their cooperation without which this study would not have materialised.

\section{References}

[1] World Health Organisation. 1992. ICD-10, International Classification of Diseases and Health Related Problems, 10th revision. World Health Organisation, Geneva, Switzerland.

[2] Robertson, M. M. 2000. "Tourette Syndrome, Associated Conditions and the Complexities of Treatment." Brain 123 (3): 425-62.

[3] American Psychiatric Association. 2000. Diagnostic and Statistical Manual of Mental Disorders. 4th Edition, Text Revision (DSM-IV-TR). Washington DC: American Psychiatric Association.

[4] Leckman, J. F., Zhang, H., Vitale, A. Lahnin, F., Lynch, K., Bondi, C., Kim, Y. S., and Peterson, B. S. 1998. "Course of Tic Severity in Tourette Syndrome: The First Two Decades." Paediatrics 102 (1): 14-9.

[5] Rickards, H. 2010. "Tourette's Syndrome and Other Tic Disorders." Practical Neurology 10 (5): 252-9.

[6] Cavanna, A. E., Servo, S., Monaco, F., and Robertson, M. M. 2009. "The Behavioural Spectrum of Gilles de la Tourette Syndrome.” J. Neuropsychiatry Clin. Neurosci. 21 (1): 13-23

[7] Schlander, M., Schwarz, O., Rothenberger, A., and Roessner, V. 2011. "Tic Disorders: Administrative Prevalence and Co-occurrence with Attention-deficit/hyperactivity Disorder in a German Community Sample." European Psychiatry 26 (6): $370-4$.

[8] Kraft, J. T., Dalsgaard, S., Obel, C., Thomsen, P. H., Henriksen, T. B., and Scahill, L. 2012. "Prevalence and Clinical Correlates of Tic Disorders in a Community Sample of School-age Children." European Child and Adolescent Psychiatry 21 (1): 5-13

[9] Zohar, A. H., Ratzoni, G., Pauls, D. L., Apter, A., Bleich, A., Kron, S., Rappaport, M., Weizman, A., and Cohen, D. J. 1992. "An Epidemiological Study of Obsessive-compulsive Disorder and Related Disorders in Israeli adolescents." Journal of the American Academy of Child \& Adolescent Psychiatry 31 (6): 1057-61.

[10] Khalifa, N., and von Knorring, A. L. 2005. "Tourette Syndrome and Other Tic Disorders in a Total Population of Children: Clinical Assessment and Background." Acta Paediatrica 94 (11): 1608-14. 
[11] Eddy, C. M., Cavanna, A. E., Gulisano, M. Calli, P., Robertson, M. M., and Rizzo, R. 2012. "The Effects of Comorbid Obsessive-compulsive Disorder and Attention-deficit Hyperactivity Disorder on Quality of Life in Tourette Syndrome." Journal of Neuropsychiatry and Clinical Neurosciences 24 (4): 458-62.

[12] Robertson, M. M. 2008. "The Prevalence and Epidemiology of Gilles de la Tourette Syndrome. Part 1: The Epidemiological and Prevalence Studies." Journal of Psychosomatic Research 65 (5): 461-72.

[13] Robertson, M. M. 2008b. "The Prevalence and Epidemiology of Gilles de la Tourette Syndrome. Part 2: Tentative Explanations for Differing Prevalence Figures in GTS, Including the Possible Effects of Psychopathology, Aetiology, Cultural Differences, and Differing Phenotypes." Journal of Psychosomatic Research 65 (5): 473-86.

[14] Robertson, M. M., Eapen, V., and Cavanna, A. E. 2009. "The International Prevalence, Epidemiology, and Clinical Phenomenology of Tourette Syndrome: A Cross-cultural Perspective." Journal of Psychosomatic Research 67 (6): 475-83.

[15] Caine, E. D., McBride, M. C., Chiverton, P., Bamford, K. A., Rediess, S., and Shiao, J. 1988. "Tourette Syndomre in Monroe County School Children.” Neurology 38 (3): $472-5$.

[16] Robertson, M. M., Verrill, M., Mercer, M., James B., and Pauls D. L. 1994. "Tourette's Syndrome in New Zealand. A Postal Survey." British Journal of Psychiatry 164 (FEB): 263-6.

[17] Mason, A., Banerjee, S., Eapen, V., Zeitlin, H., and Robertson, M. M. 1998. "The Prevalence of Tourette Syndrome in a Mainstream School Population." Developmental Medicine \& Child Neurology 40 (5): 292-6.

[18] Khalifa, N., and von Knorring, A. L. 2003. "Prevalence of Tic Disorders and Tourette Syndrome in a Swedish School Population." Developmental Medicine \& Child Neurology 45 (5): 315-9.

[19] Stefanoff, P., Wolanczyk, T., Gawrys, A., Swirszcz, K., Stefanoff, E., Kaminska, A., Lojewska-Bajbus, M., Mazurek, B., Majewska-Stefaniak, A., Mikulska, J., and Brynska, A. 2008. "Prevalence of Tic Disorders among Schoolchildren in Warsaw, Poland." European Child \& Adolescent Psychiatry 17 (3): 171-8.

[20] Cubo, E., Gabriel y Galán, J. M., Villaverde, V. A., Velasco, S. S., Benito, V. D., Macarrón, J. V., Guevara, J. C., Louis, E. D., and Benito-León, J. 2011. "Prevalence of Tics in Schoolchildren in Central Spain: A Population-based Study." Paediatric Neurology 45 (2): 100-8.
[21] Nomoto, F., and Machiyama, Y. 1990. "An Epidemiological Study of Tics." Japan Journal of Psychiatry and Neurology 44 (4): 649-55.

[22] Wong, C. K., and Lau, J. T. 1992. "Psychiatric Morbidity in a Chinese Primary School in Hong Kong." Australian and New Zealand Journal of Psychiatry 26 (3): 459-66.

[23] Jin, R., Wen-wu, H., Hui-qin, X., Hong, C., and Liang, F. 2005. "Epidemiological Survey of Tourette Syndrome in Children and Adolescents in Wenzhou of P.R. China." European Journal of Epidemiology 20 (11): 925-7.

[24] Wang, H. S., and Kuo, M. F. 2003. “Tourette's Syndrome in Taiwan: An Epidemiological Study of Tic Disorders in An Elementary School at Taipei County." Brain and Development 25 (Suppl. 1): S29-31.

[25] Apter, A., Pauls, D. L., Bleich, A. Zohar, A. H., Kron, S., Ratzoni, G., Dycian, A., Kotler, M., Weizman, A., and Gadot N. 1993. "An Epidemiologic Study of Gilles de laTourette Syndrome in Israel." Archives of General Psychiatry 50 (9): 734-8.

[26] Goodman, R. 1997. "The Strengths and Difficulties Questionnaire: A Research Note." Journal of Child Psychology and Psychiatry 38 (5): 581-6.

[27] Leckman, J. F., Riddle, M. A., Hardin, M. T. Ort, S. J., Swartz, K. L., Stevenson, J., and Cohen, D. J. 1989. "The Yale Global Tic Severity Scale: Initial Testing of a Clinician-rated Scale of Tic Severity." Journal of the American Academic of Child and Adolescent Psychiatry 28 (4): 566-73.

[28] Knight, T., Steeves, T., Day, L., Lowerison. M., Jette, N., and Pringsheim, T. 2012. "Prevalence of Tic Disorders: A Systematic Review and Meta-analysis." Paediatric Neurology 47 (2): 77-90.

[29] Singer, H. S. 2005. "Tourette's Syndrome: From Behaviour to Biology." Lancet 4 (3):149-59.

[30] Lanzi, G., Zambrino, C. A., Termine, C., Palestra, M., Ferrari Ginevra, O., Orcesi, S., Manfredi, P., and Beghi, E. 2004. "Prevalence of Tic Disorders among Primary School Students in the City of Pavia, Italy." Archives of Disease in Childhood 89 (1): 45-7.

[31] Hornsey, H., Banerjee, S., Zeitlin, H., and Robertson, M. 2001. "The Prevalence of Tourette Syndrome in 13-14-Year-Olds in Mainstream Schools." Journal of Child Psychology \& Psychiatry \& Allied Disciplines 42 (8): 1035-9.

[32] Linazasoro, G., Van Blercom, N., and de Zarate C. O. 2006. "Prevalence of Tic Disorder in Two Schools in the Basque Country: Results and Methodological Caveats." Movement Disorders 21 (12): 2106-9.

[33] Walkup, J. T., Ferraro, Y, Leckman, J. F., Stein, D. J., and Singer, H. 2010. "Tic Disorders: Some Key Issues for DSM V.” Depression and Anxiety 27 (6): 600-10. 